\title{
ANALISIS KINERJA KEUANGAN PADA PERUSAHAAN TELEKOMUNIKASI YANG TERDAFTAR DALAM BURSA EFEK INDONESIA TAHUN 2015-2017
}

\author{
Annisa Nugraheni $^{1)}$, Bambang Mursito ${ }^{2)}$, Sudarwati $^{3)}$ \\ Fakultas Ekonomi Manajemen Universitas Islam Batik Surakarta 1)2)3) \\ annisanugraheni@gmail.com
}

\begin{abstract}
The purpose of this study was to analyze and assess the financial performance of telecommunication companies listed on the Stock Exchange in 2015-2017 based on financial ratio analysis consisting of: liquidity ratios, solvability ratios, activity ratios and profitability ratios. This type of research is descriptive. Data analysis techniques used are financial ratios with time series calculations and cross sections. The research results based on overall financial ratios show that PT Telekomunikasi Indonesia has the best financial performance compared to other similar companies.
\end{abstract}

Keywords : Financial Performance, Liquidity Ratio, Solvability Ratio, Activity Ratio, Profitability Ratio

\section{PENDAHULUAN}

Semakin berkembangnya dunia usaha, tingkat persaingan antar perusahaa semakin ketat. Doerahman, et al (2016) menyatakan bahwa perkembangan perusahaan dapat dilihat dari unsur keuangan guna memberikan evaluasi terhadap kebijakan selanjutnya yang akan ditempuh perusahaan.

Salah satu aspek yang berperan dalam kemajuan perusahaan yaitu kinerja keuangan. Menurut Kindangen (2016) kinerja keuangan merupakan gambaran pencapaian keberhasilan kondisi keuangan perusahaan pada periode tertentu. Penilaian kinerja keuangan digunakan untuk mengetahui efektivitas operasi perusahaan dalam mencapai tujuannya.

Penilaian terhadap kinerja perusahaan dapat dilakukan dengan melakukan analisis terhadap laporan keuangan. Menurut Pongoh (2013). Laporan keuangan merupakan salah satu sarana penting untuk mengkomunikasikan informasi keuangan kepada pihak luar perusahaan. Analisis rasio keuangan merupakan salah satu alat analisis yang dapat digunakan untuk menilai kinerja keuangan perusahaan. Rasio keuangan berupa angka-angka yang diperoleh melalui pos-pos yang ada dalam laporan keuangan. Adebisi (2016) menyatakan rasio keuangan merupakan salah satu alat paling umum digunakan untuk pengambilan keputusan manajerial.

Perusahaan dibidang telekomunikasi berlomba-lomba untuk memberikan layanan yang baik untuk konsumen. Persaingan ini menuntut perusahaan untuk lebih kreatif dan inovatif dalam menciptakan teknologi baru yang nantinya berguna bagi perkembangan industri telekomunikasi di Indonesia (Kindangen, 2016). Dalam penelitiannya Della (2018) mengungkapkan rasio-rasio profitabilitas memiliki hubungan yang erat dengan kinerja keuangan.

\section{Rumusan Masalah}

1) Bagaimana kinerja keuangan pada perusahaan telekomunikasi yang terdaftar di Bursa Efek Indonesia tahun 2015-2017 berdasarkan rasio likuiditas?

2) Bagaimana kinerja keuangan pada perusahaan telekomunikasi yang terdaftar di Bursa Efek Indonesia tahun 2015-2017 berdasarkan rasio solvabilitas?

3) Bagaimana kinerja keuangan pada perusahaan telekomunikasi yang terdaftar di Bursa Efek 
Indonesia tahun 2015-2017 berdasarkan rasio aktivitas?

4) Bagaimana kinerja keuangan pada perusahaan telekomunikasi yang terdaftar di Bursa Efek Indonesia tahun 2015-2017 berdasarkan rasio profitabilitas?

\section{Tujuan Penelitian}

1) Untuk menganalisis dan menilai kinerja keuangan pada perusahaan telekomunikasi yang terdaftar di Bursa Efek Indonesia tahun 2015-2017 berdasarkan rasio likuiditas.

2) Untuk menganalisis dan menilai kinerja keuangan pada perusahaan telekomunikasi yang terdaftar di Bursa Efek Indonesia tahun 2015-2017 berdasarkan rasio solvabilitas.

3) Untuk menganalisis dan menilai kinerja keuangan pada perusahaan telekomunikasi yang terdaftar di Bursa Efek Indonesia tahun 2015-2017 berdasarkan rasio aktivitas.

4) Untuk menganalisis dan menilai kinerja keuangan pada perusahaan telekomunikasi yang terdaftar di Bursa Efek Indonesia tahun 2015-2017 berdasarkan rasio profitabilitas.

\section{LANDASAN TEORI}

\section{Pengertian Laporan Keuangan}

Laporan keuangan adalah suatu informasi yang menggambarkan kondisi keuangan perusahaan, dan informasi yang lebih jauh dapat digunakan sebagai gambaran kinerja perusahaan tersebut (Fahmi, 2014: 31)

\section{Analisis Laporan Keuangan}

Analisis laporan keuangan adalah kegiatan membandingkan kinerja perusahaan dalam bentuk angka-angka keuangan dengan perusahaan sejenis atau dengan

angka-angka periode sebelumnya (Utari et al, 2014: 53). Hasil perbandingan itu bisa baik, wajar atau buruk.

\section{Analisis Rasio Keuangan}

Salah satu alat analisis yang paling populer dan banyak digunakan yaitu analisis rasio.

Analisis rasio menyatakan hubungan matematis antara dua kuantitas.

(Subramanyam dan Wild, 2012:41) Jenis-jenis

rasio keuangan yaitu :

1. Rasio Likuiditas adalah kemampuan perusahaan dalam memenuhi kewajiban jangka pendek tepat waktu. Rasio ini terdiri dari :

a. Current ratio yaitu rasio yang menunjukkan kemampuan perusahaan untuk membayar kewajiban jangka pendek dengan aktiva lancar.

b. Quick ratio yaitu rasio yang menunjukkan kemampuan perusahaan untuk memenuhi kewajiban jangka pendek dengan aktiva tanpa memperhitungkan nilai persediaan.

2. Rasio solvabilitas adalah kemampuan perusahaan untuk memenuhi kewajiban jangka pendak maupun jangka panjang. Rasio ini terdiri dari

a) Debt to Assets Ratio yaitu rasio yang menunjukkan seberapa besar aktiva perusahaan yang dibiayai oleh hutang.

b) Debt to Equity Ratio yaitu rasio yang digunakan untuk menilai utang dengan ekuitas. 
3. Rasio aktivitas adalah rasio yang menunjukkan seberapa besar efektivitas perusahaan dalam menggunakan sumber dananya. Rasio ini terdiri dari :

a. Total Assets Turnover yaitu rasio yang digunakan untuk mengukur

b. keefektifan total aset yang dimiliki perusahaan dalam menghasilkan penjualan

c. Fixed Assets Turnover yaitu rasio yang melihat sejauh mana aktiva tetap yang dimiliki perusahaan terjadi perputaran secara efektif.

4. Rasio profitabilitas adalah rasio yang dapat mengukur kemampuan perusahaan dalam meghasilkan laba. Rasio ini terdiri dari :

a. Net Profit Margin. Rasio ini menunjukkan kemampuan perusahaan dalam menghasilkan laba pada penjualan tertentu.

b. Return On Asset. Rasio ini menunjukkan aktiva perusahaan memperoleh laba dari operasi perusahaan.

c. Return On Equity. Rasio ini digunakan untuk mengukur kemampuan perusahaan dalam menghasilkan laba yang tersedia bagi pemegang saham perusahaan.

\section{Kinerja Keuangan Perusahaan}

Fahmi (2014: 2) menyatakan bahwa kinerja keuangan merupakan suatu analisis yang dilakukan untuk melihat sejauh mana perusahaan telah melaksanakan dengan aturan pelaksanaan keuangan dengan baik dan benar. Seperti membuat laporan sesuai dengan ketentuan SAK (Standar Akuntansi Indonesia) atau GAAP (General Acepted Accounting Principle) dan lainnya.

\section{METODE ANALISIS DATA}

\section{Desain Penelitian}

Jenis penelitian yang digunakan dalam penelitian ini adalah deskriptif. Menurut

Norbuko dan Achmadi (2017: 44) penelitian deskriptif yaitu mengumpulkan, mengklasifikasikan, menganalisis data-data yang diperoleh perusahaan sehingga dapat memberikan gambaran keadaan yang sebenarnya.

\section{Teknik Analisis Data}

Teknik analisis data yang digunakan dalam penelitian ini menggunakan rasio keuangan. Rumus yang digunakan untuk menghitung rasio keuangan adalah sebagai berikut (Fahmi, 2014: 70) :

1) Rasio Likuiditas

a) Current Ratio

b) Quick Ratio

$$
\mathrm{QR}=\begin{aligned}
& R \stackrel{\text { Aset Lancar }}{=} \frac{}{\text { Hutang Lancar }} \\
& \frac{\text { Aset Lancar }- \text { Persediaan }}{\text { Hutang Lancar }}
\end{aligned}
$$


2) Rasio Solvabilitas

a) Debt to Assets Ratio

b) Debt to Equity Ratio

$$
\mathrm{D} A R=\frac{\text { Total Hutang }}{\text { Total Aset }}
$$

3) Rasio Aktivitas

$$
\mathrm{DE} R=\frac{\text { Total Hutang }}{\text { Total Modal Sendiri }}
$$

a) Total Assets Turnover

b) Fixed Asset Turnover

$$
\frac{\text { Penjualan }}{\text { Total Aset }}
$$

4) Rasio Profitabilitas

$$
\text { FAT }=\frac{\text { Penjualan }}{\text { Total Aktiva Tetap }}
$$

a) Net Profit Margin

b) Return On Asset

$$
\mathrm{NPM}=\frac{\text { Laba setelah pajak }}{\text { Penjualan }}
$$

c) Return On Equity

$$
\begin{aligned}
& R O A=\frac{\text { Laba setelah pajak }}{\text { Total Asset }} \\
& R O E=\frac{\text { Laba setelah pajak }}{\text { Modal Sendiri }}
\end{aligned}
$$

Pada umumnya digunakan dua cara untuk menafsirkan rasio-rasio keuangan. Menurut Fahmi (2012: 138) Teknik yang digunakan untuk menafsirkan rasio- rasio keuangan yang dihitung adalah sebagai berikut:

1) Cross Section adalah suatu teknik analisis yang dilakukan dengan membandingkan suatu hasil hitungan, antara satu perusahaan dengan perusahaan lainnya yang sejenis dalam kurun waktu yang sama.

2) Time series adalah teknik analisis yang dilakukan dengan membandingkan waktu atau periode dengan tujuan agar hasil yang terlihat dalam bentuk angka ataupun grafik.

\section{HASIL DAN PEMBAHASAN}

Kinerja Keuangan Perusahaan Telekomunikasi yang Terdaftar di BEI Tahun 2015-2017 Berdasarkan Rasio Likuiditas

\section{Current Ratio}

Tabel 1

Hasil Perhitungan Current Ratio Tahun 2015-2017

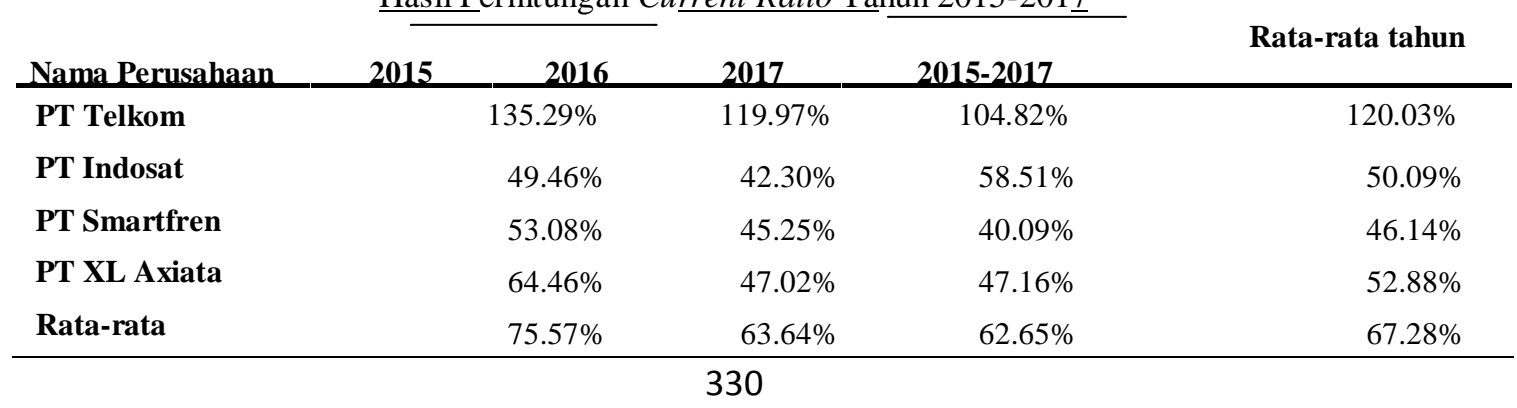


Dari perhitungan diatas, terlihat bahwa pada tahun 2015-2017 PT Telekomunikasi Indonesia memiliki rasio yang paling tinggi. Dan rasio tertinggi PT Telekomunikasi Indonesia yaitu tahun 2015 dengan current ratio sebesar $135,29 \%$ yang menunjukkan bahwa perusahaan menjadi yang terbaik dalam hal membayar hutang jangka pendek dengan aset lancar yang dimilikinya dibanding perusahaan sejenis. Sementara itu PT Smartfren Telecom memiliki rasio yang terendah diantara perusahaan telekomunikasi dengan rasio sebesar 40,09\% yaitu tahun 2017.

\section{Quick Ratio}

Tabel 2

Hasil Perhitungan Quick Ratio Tahun 2015-2017

\begin{tabular}{|c|c|c|c|c|c|}
\hline \multirow[b]{2}{*}{ Nama Perusahaan } & \multirow[b]{2}{*}{2015} & \multirow[b]{2}{*}{2016} & \multirow[b]{2}{*}{2017} & \multirow[b]{2}{*}{ 2015-2017 } & \multirow[t]{2}{*}{ Rata-rata tahun } \\
\hline & & & & & \\
\hline \multicolumn{6}{|l|}{ PT Telekomunikasi } \\
\hline Indonesia & $133.80 \%$ & & $118.50 \%$ & $103.42 \%$ & $118.58 \%$ \\
\hline PT Indosat & $49.27 \%$ & & $41.88 \%$ & $57.97 \%$ & $49.71 \%$ \\
\hline PT Smartfren & $43.16 \%$ & & $39.52 \%$ & $34.13 \%$ & $38.94 \%$ \\
\hline PT XL Axiata & $63.96 \%$ & & $45.91 \%$ & $46.22 \%$ & $52.03 \%$ \\
\hline Rata-rata & $72.55 \%$ & $61.45 \%$ & $60.44 \%$ & $64.81 \%$ & \\
\hline
\end{tabular}

Dari perhitungan diatas, terlihat bahwa pada tahun 2015-2017 PT Telekomunikasi Indonesia memiliki rasio yang paling tinggi. Dan rasio tertinggi PT Telekomunikasi Indonesia yaitu tahun 2015 dengan quick ratio sebesar 133,80\% yang menunjukkan bahwa perusahaan menjadi yang terbaik dalam hal kemampuan membayar hutang jangka pendek dengan lancar tanpa harus memperhitungkan nilai persediaan.yang dimiliki daripada perusahaan lainnya. Sementara itu PT Smartfren Telecom memiliki rasio yang terendah diantara perusahaan telekomunikasi dengan rasio sebesar 34,13\% yaitu tahun 2017.

\section{Kinerja Keuangan Perusahaan Telekomunikasi yang Terdaftar di BEI Tahun 2015-2017 Berdasarkan Rasio Solvabilitas \\ Debt to Assets Ratio}

Tabel 3

Hasil Perhitungan Debt to Assets Ratio Tahun 2015-2017

\begin{tabular}{llllr}
\hline \multicolumn{1}{c}{ Nama Perusahaan } & $\mathbf{2 0 1 5}$ & $\mathbf{2 0 1 6}$ & $\mathbf{2 0 1 7}$ & $\begin{array}{c}\text { Rata-rata tahun } \\
\mathbf{2 0 1 5 - 2 0 1 7}\end{array}$ \\
\hline PT Telkom & $43.78 \%$ & $41.24 \%$ & $43.51 \%$ & $42.84 \%$ \\
PT Indosat & $76.05 \%$ & $72.11 \%$ & $70.76 \%$ & $72.97 \%$ \\
PT Smartfren & $66.92 \%$ & $74.27 \%$ & $61.66 \%$ & $67.62 \%$ \\
PT XL Axiata & $76.05 \%$ & $61.37 \%$ & $61.59 \%$ & $66.34 \%$ \\
Rata-rata & $65.70 \%$ & $62.25 \%$ & $59.38 \%$ & $62.44 \%$ \\
\hline
\end{tabular}

Dari perhitungan diatas, terlihat bahwa pada tahun 2015-2017 PT Telekomunikasi Indonesia memiliki rasio yang terendah. Dan rasio terendah PT Telekomunikasi Indonesia yaitu tahun 2016 dengan debt to assets ratio sebesar 41,24\% karena semakin kecil rasio ini menunjukkan bahwa sedikitnya aset perusahaan yang dibiayai oleh hutang. Sementara itu PT Indosat memiliki rasio yang tetinggi 
diantara perusahaan telekomunikasi dengan rasio sebesar $76.05 \%$ yaitu tahun 2015 .

\section{Debt to Equity Ratio}

Tabel 4

Hasil Perhitungan Debt to Equity Ratio Tahun 2015-2017

\begin{tabular}{|c|c|c|c|c|}
\hline Nama Perusahaan & 2015 & 2016 & 2017 & $\begin{array}{c}\text { Rata-rata tahun } \\
2015-2017\end{array}$ \\
\hline PT Telkom & $77.86 \%$ & $70.18 \%$ & $77.01 \%$ & $75.02 \%$ \\
\hline PT Indosat & $317.59 \%$ & $258.60 \%$ & $241.95 \%$ & $272.71 \%$ \\
\hline PT Smartfren & $236.94 \%$ & $288.58 \%$ & $160.84 \%$ & $228.79 \%$ \\
\hline PT XL Axiata & $317.58 \%$ & $158.83 \%$ & $160.38 \%$ & $212.26 \%$ \\
\hline Rata-rata & $237.49 \%$ & $194.05 \%$ & $160.05 \%$ & $197.20 \%$ \\
\hline
\end{tabular}

Dari perhitungan diatas, terlihat bahwa pada tahun 2015-2017 PT Telekomunikasi Indonesia memiliki rasio yang terendah. Dan rasio terendah PT Telekomunikasi Indonesia yaitu tahun 2016 dengan debt to equity ratio sebesar 70,18\% karena semakin kecil rasio ini maka semakin besar pula jaminan keamanan yang didapatkan kreditor. Sementara itu PT Indosat memiliki rasio yang tertinggi diantara perusahaan telekomunikasi dengan rasio sebesar $317,59 \%$ yaitu tahun 2015.

\section{Kinerja Keuangan Perusahaan Telekomunikasi yang Terdaftar di BEI Tahun 2015-2017 Berdasarkan Rasio Aktivitas \\ Total Assets Turnover}

Tabel 5

Hasil Perhitungan Total Assets Turnover Tahun 2015-2017

\begin{tabular}{lcccr}
\hline Nama Perusahaan & 2015 & 2016 & 2017 & $\begin{array}{c}\text { Rata-rata tahun } \\
\text { 2015-2017 }\end{array}$ \\
\hline PT Telkom & $61.66 \%$ & $64.77 \%$ & $64.62 \%$ & $63.68 \%$ \\
PT Indosat & $48.33 \%$ & $57.41 \%$ & $59.07 \%$ & $54.94 \%$ \\
PT Smartfren & $14.61 \%$ & $15.95 \%$ & $19.36 \%$ & $16.64 \%$ \\
PT XL Axiata & $38.88 \%$ & $38.88 \%$ & $40.62 \%$ & $39.46 \%$ \\
Rata-rata & $40.87 \%$ & $44.25 \%$ & $45.92 \%$ & $43.68 \%$ \\
\hline
\end{tabular}

Dari perhitungan diatas, terlihat bahwa pada tahun 2015-2017 PT Telekomunikasi Indonesia memiliki rasio yang paling tinggi. Dan rasio tertinggi PT Telekomunikasi Indonesia yaitu tahun 2016 dengan total assets turnover sebesar $64,77 \%$ menunjukkan bahwa perusahaan menjadi yang terbaik dalam menggunakan total aset secara efektif dalam menghasilkan penjualan daripada perusahaan sejenis lainnya. Sementara itu PT Smartfren Telecom memiliki rasio yang terendah diantara perusahaan telekomunikasi dengan rasio sebesar $14,61 \%$ yaitu tahun 2015. 
Fixed Assets Turnover

Tabel 6

Hasil Perhitungan Fixed Assets Turnover Tahun 2015-2017

\begin{tabular}{lrrrrr}
\hline \multicolumn{1}{c}{ Nama Perusahaan } & \multicolumn{2}{c}{2015} & & & \multicolumn{2}{c}{ Rata-rata Tahun } \\
\cline { 1 - 2 } PT Telkom & $98.81 \%$ & $101.60 \%$ & $98.53 \%$ & $2015-2017$ \\
PT Indosat & $64.01 \%$ & $74.68 \%$ & $83.38 \%$ & $99.65 \%$ \\
PT Smartfren & $23.32 \%$ & $28.71 \%$ & $31.08 \%$ & $74.02 \%$ \\
PT XL Axiata & $68.44 \%$ & $64.31 \%$ & $65.48 \%$ & $27.70 \%$ \\
Rata-rata & $63.65 \%$ & $67.33 \%$ & $69.62 \%$ & $66.08 \%$ \\
\hline Dari perhitungan diatas, terlihat bahwa pada tahun 2015-2017 PT Telekomunikasi \\
Indonesia memiliki rasio yang paling tinggi. Dan rasio tertinggi PT \\
Telekomunikasi Indonesia yaitu tahun 2016 dengan fixed assets turnover sebesar \\
101,60\% menunjukkan bahwa perusahaan menjadi yang terbaik dalam \\
menggunakan aset tetap secara efektif dalam menghasilkan penjualan daripada \\
perusahaan lainnya. Sementara itu PT Smartfren Telecom memiliki rasio yang \\
terendah diantara perusahaan telekomunikasi dengan rasio sebesar 23,32\% yaitu \\
tahun 2015
\end{tabular}

\section{Kinerja Keuangan Perusahaan Telekomunikasi yang Terdaftar di BEI Tahun 2015-2017 Berdasarkan Rasio Profitabilitas Net Profit Margin}

Tabel 7

Hasil Perhitungan Net Profit Margin Tahun 2015-2017

\begin{tabular}{|c|c|c|c|c|}
\hline Nama Perusahaan & 2015 & 2016 & 2017 & $\begin{array}{c}\text { Rata-rata Tahun } \\
2015-2017\end{array}$ \\
\hline PT Telkom & $22.75 \%$ & $25.08 \%$ & $25.50 \%$ & $24.44 \%$ \\
\hline PT Indosat & $-4.35 \%$ & $4.37 \%$ & $4.35 \%$ & $1.46 \%$ \\
\hline PT Smartfren & $-51.74 \%$ & $-54.28 \%$ & $-64.75 \%$ & $-56.92 \%$ \\
\hline PT XL Axiata & $-0.11 \%$ & $1.76 \%$ & $1.64 \%$ & $1.10 \%$ \\
\hline Rata-rata & $-8.36 \%$ & $-5.77 \%$ & $-8.32 \%$ & $-7.48 \%$ \\
\hline \multicolumn{5}{|c|}{$\begin{array}{l}\text { Dari perhitungan diatas, terlihat bahwa pada tahun 2015-2017 PT Telekomunikasi } \\
\text { Indonesia memiliki rasio yang paling tinggi. Dan rasio tertinggi PT } \\
\text { Telekomunikasi Indonesia yaitu tahun } 2017 \text { dengan net profit margin sebesar } \\
25,50 \% \text { yang menunjukkan bahwa perusahaan menjadi yang terbaik dalam menghasilkan } \\
\text { laba bersih dari penjualan daripada perusahaan sejenis lainnya. Sementara itu PT } \\
\text { Smartfren Telecom memiliki rasio yang terendah diantara perusahaan telekomunikasi } \\
\text { dengan rasio sebesar - } 64.75 \% \text { yaitu tahun } 2017 \text {. }\end{array}$} \\
\hline
\end{tabular}


Return On Assets

Tabel 8

Hasil Perhitungan Return On Assets Tahun 2015-2017

\begin{tabular}{|c|c|c|c|c|}
\hline \multirow[b]{2}{*}{ Nama Perusahaan } & \multirow[b]{2}{*}{2015} & \multirow[b]{2}{*}{2016} & \multicolumn{2}{|c|}{ Rata-rata Tahun } \\
\hline & & & 2017 & 2015-2017 \\
\hline PT Telkom & $14.03 \%$ & $16.24 \%$ & $16.48 \%$ & $15.58 \%$ \\
\hline PT Indosat & $-2.10 \%$ & $2.51 \%$ & $2.57 \%$ & $0.99 \%$ \\
\hline PT Smartfren & $-7.56 \%$ & $-8.66 \%$ & $-12.53 \%$ & $-9.58 \%$ \\
\hline PT XL Axiata & $-0.04 \%$ & $0.68 \%$ & $0.67 \%$ & $0.44 \%$ \\
\hline Rata-rata & $1.08 \%$ & $2.69 \%$ & $1.80 \%$ & \\
\hline \multicolumn{5}{|l|}{$1.86 \%$} \\
\hline \multicolumn{5}{|c|}{$\begin{array}{l}\text { Dari perhitungan diatas, terlihat bahwa pada tahun 2015-2017 PT Telekomunikasi } \\
\text { Indonesia memiliki rasio yang paling tinggi. Dan rasio tertinggi PT } \\
\text { Telekomunikasi Indonesia yaitu tahun } 2017 \text { dengan return on assets sebesar } \\
16,48 \% \text { menunjukkan bahwa perusahaan menjadi yang terbaik dalam } \\
\text { menghasilkan setiap rupiah yang ditanamkan dalam total aset daripada perusahaan } \\
\text { lainnya. Sementara itu PT Smartfren Telecom memiliki rasio yang terendah } \\
\text { diantara perusahaan telekomunikasi dengan rasio sebesar }-12.53 \% \text { yaitu tahun } \\
\text { 2017. }\end{array}$} \\
\hline
\end{tabular}

Return On Equity

Tabel 9

Hasil Perhitungan Return On Equity Tahun 2015-2017

\begin{tabular}{lcccrr}
\hline & & & \multicolumn{2}{c}{ Rata-rata Tahun } \\
\cline { 1 - 2 } \multicolumn{1}{c}{ PT Telkom Perusahaan } & $\mathbf{2 0 1 5}$ & & $\mathbf{2 0 1 6}$ & $\mathbf{2 0 1 7}$ & $\mathbf{2 0 1 5 - 2 0 1 7}$ \\
PT Indosat & $24.96 \%$ & $27.64 \%$ & $29.16 \%$ & $27.25 \%$ \\
PT Smartfren & $-8.77 \%$ & $9.00 \%$ & $8.79 \%$ & $3.00 \%$ \\
PT XL Axiata & $-26.77 \%$ & $-33.64 \%$ & $-32.70 \%$ & $-31.03 \%$ \\
Rata-rata & $-0.18 \%$ & $1.77 \%$ & $1.73 \%$ & $1.11 \%$ \\
\hline
\end{tabular}

Dari perhitungan diatas, terlihat bahwa pada tahun 2015-2017 PT Telekomunikasi Indonesia memiliki rasio yang paling tinggi. Dan rasio tertinggi PT Telekomunikasi Indonesia yaitu tahun 2017 dengan return on equity sebesar $29,16 \%$ yang menunjukkan bahwa perusahaan menjadi yang terbaik dalam menghasilkan setiap rupiah yang ditanamkan dalam total ekuitas daripada perusahaan sejenis lainnya. Sementara itu PT Smartfren Telecom memiliki rasio yang terendah diantara keempat perusahaan telekomunikasi dengan rasio sebesar $-33,64 \%$ yaitu tahun 2016 .

\section{KESIMPULAN}

Berdasarkan hasil perhitungan rasio keuangan pada laporan keuangan perusahaan telekomunikasi yang terdaftar dalam Bursa Efek Indonesia dari tahun 2015 sampai dengan tahun 2017, maka dapat disimpulkan bahwa :

1) Dilihat dari segi rasio likuiditas menggunakan Current Ratio, PT Telekomunikasi Indonesia menjadi yang terbaik dalam hal membayar hutang jangka 
pendek dengan aset lancar yang dimilikinya dibandingkan dengan perusahaan sejenis, sementara itu PT Smartfren Telecom memiliki rasio yang terendah diantara perusahaan telekomunikasi Jika dilihat dari Quick Ratio, PT Telekomunikasi Indonesia menjadi yang terbaik dalam hal kemampuan membayar hutang jangka pendek dengan lancar tanpa harus memperhitungkan nilai persediaan yang dimiliki daripada perusahaan lainnya, sementara itu PT Smartfren Telecom memiliki rasio yang terendah diantara perusahaan telekomunikasi

2) Dilihat dari segi rasio solvabilitas menggunakan Debt To Assets Ratio, PT Telekomunikasi Indonesia menjadi yang terendah, sementara itu PT Indosat memiliki rasio yang tetinggi diantara perusahaan telekomunikasi. Jika dilihat dari Debt to Equity Ratio PT Telekomunikasi Indonesia memiliki rasio yang terendah karena semakin kecil rasio ini maka semakin besar pula jaminan keamanan yang didapatkan kreditor, Sementara itu PT Indosat memiliki rasio yang tertinggi diantara perusahaan telekomunikasi.

3) Dilihat dari segi rasio aktivitas menggunakan Total Assets Turnover PT Telekomunikasi Indonesia memiliki rasio yang tertinggi menunjukkan bahwa perusahaan menjadi yang terbaik dalam menggunakan total aset secara efektif dalam menghasilkan penjualan daripada perusahaan sejenis lainnya, sementara PT Smartfren Telecom memiliki rasio yang terendah. Jika dilihat dari Fixed Assets Turnover PT Telekomunikasi Indonesia memiliki rasio yang tertinggi menunjukkan bahwa perusahaan menjadi yang terbaik dalam menggunakan aset tetap secara efektif dalam menghasilkan penjualan daripada perusahaan lainnya, sementara PT Smartfren Telecom memiliki rasio yang terendah diantara perusahaan telekomunikasi.

4) Dilihat dari segi rasio profitabilitas menggunakan Net Profit Margin PT Telekomunikasi Indonesia memiliki rasio yang tertinggi yang menunjukkan bahwa perusahaan menjadi yang terbaik dalam menghasilkan laba bersih dari penjualan daripada perusahaan sejenis lainnya, Sementara itu PT Smartfren Telecom memiliki rasio yang terendah diantara perusahaan telekomunikasi. Jika dilihat dari Return On Assets PT Telekomunikasi Indonesia memiliki rasio tertinggi menunjukkan bahwa perusahaan menjadi yang terbaik dalam menghasilkan setiap rupiah yang ditanamkan dalam total aset daripada perusahaan lainnya, Sementara itu PT Smartfren Telecom memiliki rasio yang terendah, sementara itu PT Smartfren Telecom memiliki rasio yang terendah. Jika dilihat dari Return On Equity PT Telekomunikasi Indonesia memiliki rasio tertinggi menunjukkan bahwa perusahaan menjadi yang terbaik dalam menghasilkan setiap rupiah yang ditanamkan dalam total ekuitas daripada perusahaan sejenis, itu PT Smartfren Telecom memiliki rasio yang terendah diantara keempat perusahaan telekomunikasi.

\section{Saran}

1) Bagi Perusahaan Telekomunikasi sebaiknya dapat mempertahankan bahkan

2) meningkatkan kemampuannya dalam memenuhi kewajiban jangka pendeknya dengan cara meningkatkan aset lancar dan mengurangi hutang sehingga dapat optimal dalam memenuhi hutang jangka pendek.

3) Bagi Perusahaan Telekomunikasi apabila memilih sumber pendanaan dari

4) hutang jangka panjang hendaknya menganalisis keadaan keuangan lebih dulu sehingga terhindar dari bermacam resiko dimasa mendatang.

5) Bagi Perusahaan Telekomunikasi hendaknya dapat mempertahankan bahkan 
meningkatkan kemampuannya dalam menggunakan aktiva dan sumber daya yang dimiliki dengan cara meningkatkan poduktivitas dengan memerhatikan pendapatan sehingga dapat memaksimalkan dan mengembangkan strategi baru agar dapat bertahan dalam persaingan yang kompetitif.

6) Bagi Perusahaan Telekomunikasi lebih meningkatkan kemampuan dalam menghasilkan laba sehingga dapat menarik minat investor dan juga memperbaiki kinerja keuangannya.

7) Untuk peneliti dimasa mendatang disarankan agar menambahkan periode

8) pengamatan untuk mendapatkan hasil yang akurat serta menggunakan rasio keuangan bervariatif sehingga memberikan gambaran kinerja keuangan secara maksimal

\section{DAFTAR PUSTAKA}

Adebisi, Lyiola and Olayemi. 2016. The Statistical Evaluation of the Performance of Financial Ratio Analysis in Nigerian Manufacturing Industri: An Emperical Study of Guinness Nigeria PLC. Nigeria: The International Journal of Business \& Management. Volume 4.

Della Fauzi, I., \& Rukmini, R. (2018). The Effect of Financial Performance Measured With Rentability Ratio Against Dividend Payout Ratio (Empirical Study on Manufacturing Companies Group Listed on BEI). International Journal of Economics, Business and Accounting Research (IJEBAR), 2(01).

Doerachman, et al. 2016. Analisis Perbandingan Kinerja Keuangan Pada Perusahaan Farmasi yang Terdaftar di Bursa Efek Indonesia Periode 2011-2014. Manado: Jurnal Berkala Ilmiah Efisiensi. Volume 16 No 3.

Fahmi, Irham. 2012. Analisis Kinerja Keuangan. Bandung: Alfabeta .2014. Analisis Laporan Keuangan. Bandung: Alfabeta.

Kindangen, Claudia Friska. 2016. Analisis Perbandingan Kinerja Keuangan Pada Perusahaan Telekomunikasi yang Terdaftar di Bursa Efek Indonesia Periode 20112014 (Studi Kasus PT. Telekomunikasi Indonesia Tbk dan PT. XL Axiata Tbk. Manado: Jurnal Berkala Ilmiah Efisiensi. Volume 16 No 03.

Narbuko dan Achmadi. 2016. Metodologi Penelitian. Jakarta: Bumi Aksara. Pongoh, Marsel. 2013. Analisis Laporan Keuangan Untuk Menilai Kinerja Keuangan PT. Bumi Resources Tbk. Manado: Jurnal EMBA. Volume 1 No 3.

Subramanyam dan Wild. 2012. Analisis Laporan Keuangan. Jakarta: Salemba Empat.

Utari, et al. 2014. Manajemen Keuangan Edisi Revisi. Jakarta: Mitra Wacana Media. www.idx.co.id. 